\title{
Evaluation of the Balance of Water Resources in Multiple Spatial Scale Based on Lorenz Curves and Gini Coefficients
}

\author{
Haizhen Liu ${ }^{1,2}$, Xuefeng Sang ${ }^{1,2,}$, Ziqi Yan ${ }^{1,2}$, Zuhao Zhou ${ }^{1,2}$, Jianguang $\mathrm{Su}^{3}$ and Gang $\mathrm{Chen}^{3}$ \\ ${ }^{1}$ State Key Laboratory of Simulation and Regulation of Water Cycle in River Basin, China Institute of Water Resources and \\ Hydropower Research, Beijing 100038, China \\ ${ }^{2}$ Engineering and Technology Research Center for Water resources and Hydroecology of the Ministry of Water Resources, \\ Beijing 100038, China \\ ${ }^{3}$ Yunnan Institute of Water \& Hydropower Engineering Investigation, Design and Research, Kunming 650000, China \\ *Corresponding author
}

\begin{abstract}
Influenced by special topography and threedimensional climate, the distribution of water resources in Yunnan Province is obviously different form other regions. According to the official reports of water resources, related evaluations and planning in Yunnan Province in 2012, the interaction cutting relation between administrative regions and water resource divisions was studied with geography spatial analysis method, and the areas of cutting units were calculated, by which the water resources of per capita in city, county, township level administrative regions were figured out. The Lorenz curves and Gini coefficients, which were used to describe the differential allocation of revenue in economics qualitatively and quantitatively, were introduced to study the spatial balancein different spatial scales. Gini coefficients were $0.53,0.64$ and 0.69 respectively. Results show that in the processe of downscaling, the spatial distribution of water resources in Yunnan Province is increasingly unbalanced: water resource in northwest and southwest is relatively abundant, water resources of city group, which located in central Yunnan including dry-hot valley, are relatively short, and per capita water resources are star flashed on small scale distribution, which poses a challenge to security of water resource especially when Yunnan suffers a drought.
\end{abstract}

Keywords-three-dimensional climate; water resource; balance of space; lorenz curves; gini coefficients; downscaling

\section{INTRODUCTION}

Yunnan province, lying in the southeast of China, is located at $97^{\circ} 31^{\prime} 39^{\prime \prime} \mathrm{E}$ to $106^{\circ} 11^{\prime} 47^{\prime \prime} \mathrm{E}$ and $21^{\circ} 8^{\prime} 32^{\prime \prime} \mathrm{N}$ to $29^{\circ} 15^{\prime} 8^{\prime \prime} \mathrm{N}$, with a total area of 394 thousands square kilometers, whose maximum horizontal distance is 864.9 kilometers and maximum vertical distance is 990 kilometers. From the respect of geography, Yunnan province, situated at southeastern end of the Qinghai-Tibetan Plateau, with the Pacific Ocean in the southeast and Indian Ocean in the southwest, has formed a complicated natural geographical environment due to the influences of the South Sea monsoon ${ }^{[1]}$ and the Indian summer monsoon ${ }^{[2]}$. From the respect of topography, the terrain slope tilts from the northwest to the southeast, contributing to a great difference of elevation in this region, where are separated into mountains, hills, valleys and basins with the highest latitude of 6.74 kilometers and the lowest of 76.4 meters $^{[3]}$. From the point of water development, six river systems are formed, namely Yangtze River, Pearl River, Red River, Lancang River, Nu River and Irrawaddy River, and nine plateau lakes are formed because of the faulting of lake basins, including Lugu Lake, Chenghai Lake, Dian Lake, Yangzong Lake, Xingyun Lake, Fuxian Lake, Qilu Lake, Yilong Lake and Erhai Lake ${ }^{[4]}$. T4e interaction of geography, topography, river systems and other factors contributes to the formation of a tridimensional climate distribution across seven climatic zones in Yunnan Province, with characteristics of the plateau, low latitude and monsoon climates simultaneously ${ }^{[5]}$.

Compared with other regions of China, water resources are abundant in Yunnan province, where the average annual precipitation reaches 1279 millimeters. Influenced by tridimensional climate, spatial distribution of the total rainfall is entirely imbalanced. The precipitation is concentrated in the Daying River basin in the west of Yunnan province, with the annual precipitation over 4000 millimeters. On the contrary, there is very little rain in Benzilan region alongside the Jinsha River, where the annual precipitation is merely 300 millimeters ${ }^{[6]}$. The special topography and climate conditions lead to a severe mismatch in distributions among water resources, population and social productivity, which has hindered the harmonious development of society and economy.

In order to study the distribution of water resources in Yunnan Province, Lorenz curves ${ }^{[7,8]}$ and Gini coefficients ${ }^{[9,10]}$, which were originally used to evaluate the differential allocation of revenue in economics, were introduced to study the imbalance of water resources allocation in different spatial scales. Water resources of per capita were calculated respectively on large, middle and small spatial scales, based on which Lorenz curves and Gini coefficients could be figured out. According to the evaluation criteria of Gini coefficient, the imbalance of spatial distribution of water resources was estimated qualitatively and quantitatively. 


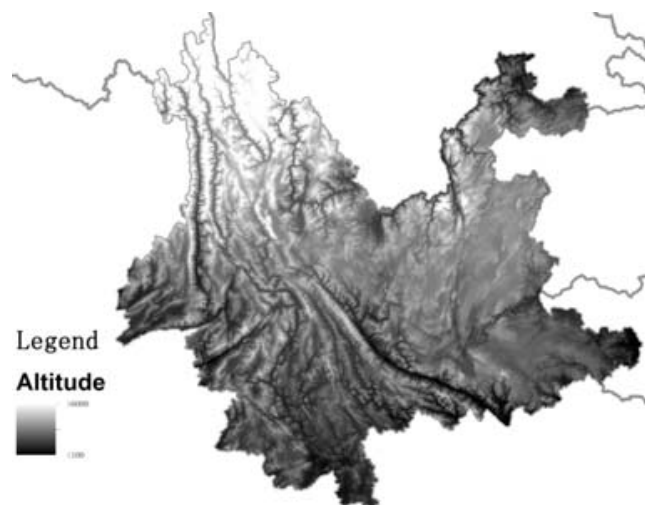

FIGURE I. TOPOGRAPHY OF YUNNAN PROVINCE.

\section{METHOD}

\section{A. Spatial Equilibrium Analysis of Water Resources}

Water resources have multiple attributes covering nature, society, economy, ecology, etc. In water shortage area, the most significant function is to meet the basic need of human lives and industry development. Water use for human beings should approach parity for individual equal right to survival and development. If only take natural attribute into account when analyze the spatial equilibrium of water resources, it is apt to study the distribution of water resources in administrative zones at different levels, which overlooks the social attribute of water resources. While equilibrium analysis of water resources should be undertook from the respect of nature-society dual attributes, emphasizing the significance of human beings in the research. In order to reflect the fairness of society, water resources of per capita was chosen as the key index to evaluate the equilibrium of water resources. Evaluation classification of per capita water resources are list in Table 1 according to relative criteria ${ }^{[11]}$.

TABLE I. EVALUATION CRITERIA OF RER CAPITA WATER RESOURCES

\begin{tabular}{|c|c|c|c|c|c|}
\hline $\begin{array}{c}\text { Water } \\
\text { resources of } \\
\text { per capita }\end{array}$ & $<500$ & $\begin{array}{c}500- \\
1000\end{array}$ & $\begin{array}{c}1000- \\
1700\end{array}$ & $\begin{array}{c}1700- \\
3000\end{array}$ & $>3000$ \\
\hline $\begin{array}{c}\text { classification } \\
\text { of water } \\
\text { shortage }\end{array}$ & extreme & severe & moderate & mild & sufficient \\
\hline
\end{tabular}

\section{B. Method of Equilibrium Evaluation of Water Resources}

In order to evaluate the spatial equilibrium of water resources, qualitative and quantitative analysis for water resources of per capita should be undertook. In the field of economics, Lorenz curves and Gini coefficients are often used to appraise the fairness of the social income distribution, which could visually reveal the structure of distribution and precisely reflect the income inequality. Lorenz curves and Gini coefficient were applied into the analysis of water consumption structure of Zhengzhou, which analyzed the spatial distribution of all types of water utilities ${ }^{[12]}$. A distribution model of water pollutants in lake basin on environment Gini coefficient was built to analyze its superiority compared with other modeling methods, including equal proportion distribution method, analytic hierarchy process method and delph method ${ }^{[13]}$. Through extending Gini coefficient connotation, the conception of environmentresource Gini coefficient was proposed to analyze China spatial difference of environment-resource distribution [14]. Drawing lessons from previous work, based on the clarity of the research content and study methods, Lorenz curves and Gini coefficients were introduced to analyze the spatial equilibrium of water resources.

\section{1) Lorenz Curve}

Lorenz curve is also called actual distribution curve, which was firstly introduced to appraise the fairness of the social income distribution by Lorenz, statistician from Austria, in 1905. It's mathematical expression is showed as (1), in which $\mu$ represents expectation, and $\mathrm{F}(\mathrm{x})$ represents cumulative distribution function of orderly series.

$$
E(y)=\frac{\int_{0}^{p} x d F(x)}{g}
$$

As is showed in Figure 2, horizontal axis represents cumulative sum of groups divided by value in ascending order, and vertical axis represents cumulative objective function values. Diagonal line indicates that allocation is absolutely fair, while rectangle polyline indicates that the allocation is totally unfair. The curve between them is Lorenz curve, whose curvature illustrates the allocation equilibrium.

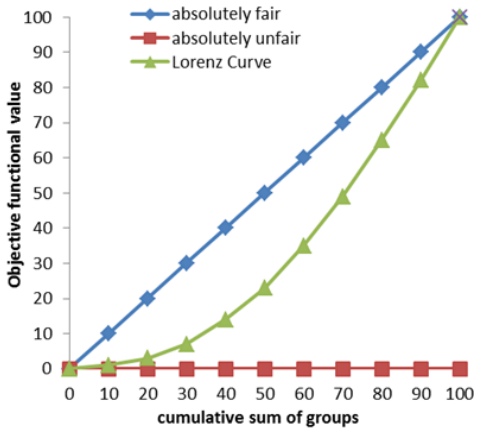

FIGURE II. LORENZ CURVES

\section{2) Gini Coefficient}

The Gini coefficient is used to measure the balance of income allocation, which was put forward by an Italian economist in 1922. Gini coefficient is also called Lorenz coefficient for it could be calculated through Lorenz curve. Assuming that the area between absolutely fair line and Lorenz curve is $\alpha$, and the area between Lorenz curve and totally unfair polyline is $\beta$. Gini coefficient ( $G$ for short) could be expressed by the ratio of $\alpha$ and the sum of $\alpha$ and $\beta$. The expression of Gini coefficient is showed as (2), in which $\mathrm{W}_{\mathrm{i}}$ represents the share of population of each group, $Y_{i}$ represents the share of the aggregate income within each group, and $V_{i}$ is the sum of $Y_{i}$. 


$$
E_{r}=\sum_{n=1}^{n} w_{t} Y_{t}+2 \sum_{i=1}^{n-1} W_{t}\left(1-v_{t} x-1\right.
$$

According to the regulations of the organizations relevant to United Nations, the evaluation criteria of Gini coefficient are showed in Table $2^{[13]}$. The reasonable threshold limit of Gini coefficient is 0.382 referring to the Golden ratio, while 0.4 is regarded as the red line of the income gap practically.

TABLE II. THE EVALUATION CRITERIA OF GINI COEFFICIENT

\begin{tabular}{|c|c|c|c|c|c|}
\hline $\begin{array}{c}\text { Gini } \\
\text { coefficient }\end{array}$ & $0.0 \sim 0.2$ & $0.2 \sim 0.3$ & $0.3 \sim 0.4$ & $0.4 \sim 0.5$ & $0.5 \sim 1.0$ \\
\hline evaluation & $\begin{array}{l}\text { Absolutel } \\
\text { y fair }\end{array}$ & $\begin{array}{l}\text { Relativ } \\
\text { ely fair }\end{array}$ & $\begin{array}{l}\text { Accept } \\
\text { able }\end{array}$ & $\begin{array}{l}\text { Relativel } \\
\text { y unfair }\end{array}$ & $\begin{array}{l}\text { Absolutely } \\
\text { unfair }\end{array}$ \\
\hline
\end{tabular}

3) Spatial Multi-Scale Decomposition

In order to ensure the integrity of the administrative region, highlight the distribution characteristics and the contradiction between supply and demand of regional water resources, and improve the accuracy and depth of research, the distribution of water resources are studied in three different spatial scales. Taking Yunnan Province as example, there are 16 prefecturelevel regions, 129 county-level regions and 1368 townshiplevel regions in Yunnan province. This article made the spatial equilibrium evaluations of water resources in city, county, township-level administrative regions respectively.

\section{SPatial EQuilibrium EVAluation OF WATER RESOURCES}

\section{A. Data Preprocessing}

Two basic data are involved in equilibrium evaluation, including population and water resources in 2012. Population data could be acquired in Yunnan Statistical Yearbook (2013), while the calculation of water resources in different spatial levels is the key part of data preprocessing. Normally, the minimum statistical caliber of water resource bulletin is county-level region, and minimum unit of water resources planning is four-level water resources area. In Yunnan Province, most groundwater will eventually grain out to supplement river base flow; therefore it is feasible to take surface water resources amount as the total amount of regional water resources. Based on the water resources evaluation, relative planning results and Yunnan Water Resources Bulletin (2012), the water resources amounts in township-level regions were calculated with geographical space distribution method on GIS platform.

\section{B. Equilibrium Evaluation of Water Resources}

Equilibrium evaluation was made through spatial distributions, Lorenz curve and Gini coefficient of water resources in three spatial scales, which were illustrated in Figure 3. From the respect of prefecture level, water resources were abundant in west and south Yunnan Province, while the middle and northeast regions were in serious water shortage, especially the capital Kunming, where the water resource of per capita was only 568 cubic meters, approaching the extreme water shortage threshold value of 500 cubic meters. By contrast, the water resource of per capita in Diqing, in the northwest of Yunnan Province, was 29725 cubic meters, indicating a huge gap of per capita water resources in prefecture level. From the respect of county level, water resources were abundant in most counties in northwest and southwest regions. Longyang, Baoshan and Fengqing, Lincang were in mild water shortage, some counties in Honghe and Wenshan were in moderate water shortage, and the counties in severe even extreme water shortage were mainly gathered in middle part of Yunnan Province, especially municipal seats and dry-hot valley. From the respect of township level, the distribution regularities of water resources were similar to that of county-level regions. In 1368 towns, there were 593 towns with per capita water resources below 3000 cubic meters, indicating a widening gap of water resources in township level. From the respect of Gini coefficient, the values in perfection, county and township levels were $0.3351,0.4757$ and 0.5389 separately, which meant the imbalance of water resources became more and more obvious in the processes of spatial downscaling.
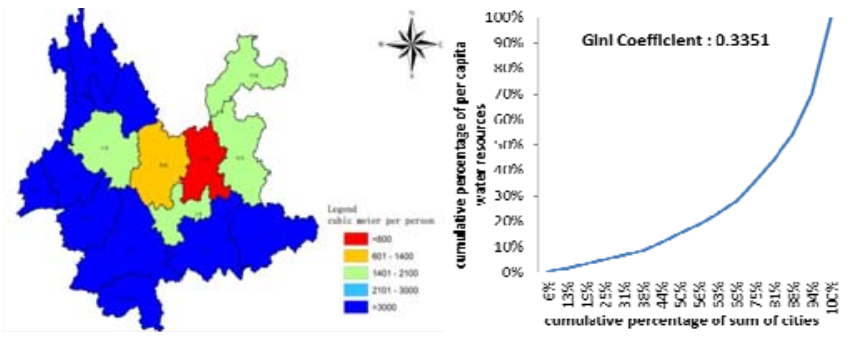

(A)
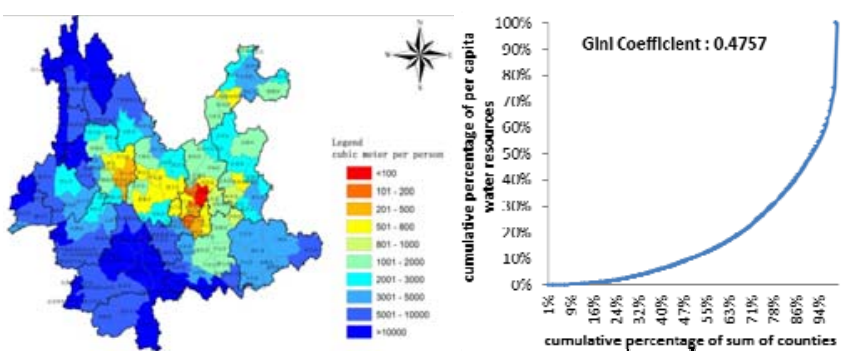

(B)

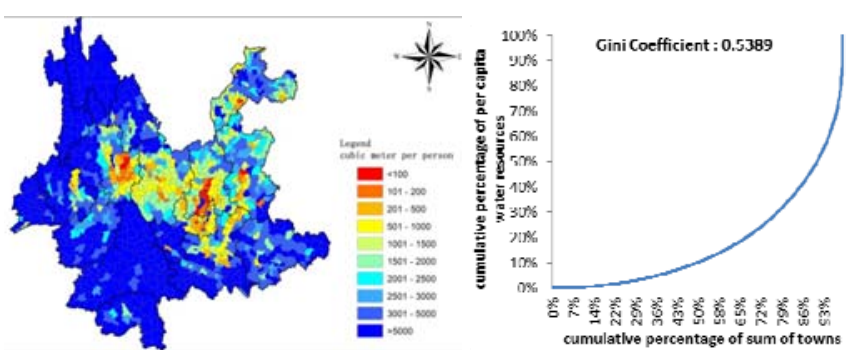

(C)

FIGURE III. EQUILIBRIUM EVALUATION OF WATER RESOURCES IN THE PROCESS OF SPATIAL DOWNSCALING, ADOPTED FROM YUNNAN STATISTICAL YEARBOOK (2013) AND YUNNAN WATER RESOURCES BULLETIN (2012). (A), (B) AND (C) ARE PER CAPITA WATER RESOURCES, LORENZ CURVE AND GINI COEFFICIENT IN CITY,COUNTY AND TOWNSHIP ADMINISTRATIVE REGIONS RESPECTIVELY. 


\section{Discussion}

As can be seen from the analysis above, in the process of spatial downscaling, the initial slope of Lorenz curves is relatively small. With the increase of the cumulative percentage of population, the rising speed of slope is accelerating, which could be testified by the increasing Gini coefficient. From the respect of city level, shortage of water resources mainly centered on cities in the middle part of Yunnan Province, and per capita water resources gap among different cities is acceptable to some extent. From the respect of county level, the shortage of water resources in some counties is more severe, while the others are not. The gap of per capita water resources among different counties has been widened. From the respect of township level, the Gini coefficient is larger than that in city and county levels, and the gap of per capita water resources among different towns is notable.

\section{CONCLUSIONS}

Influenced by special topography and three-dimensional climate, the distribution of water resources in Yunnan Province is obviously different from other regions in China. From the respect of large spatial scale, with the decreasing of elevation from northwest to southeast, the water resources in western Yunnan Province are much more abundant than that in the east part. City clusters in the middle part of Yunnan Province suffer severely from shortage of water resources. However, from respect of small spatial scale, there are still obvious distinctions in water resources among adjacent areas due to the complicated distribution of basins, valleys, hills and plateaus and different underlying surface conditions. From the respect of the per capita water resources, the figure is smaller in the densely-populated prosperous areas and vice versa, which is a big challenge to the social and economic development of Yunnan Province.

\section{ACKNOWLEDGMENT}

This study received financial supports from Major Water Conservancy Project of Yunnan Province (YSZD-2014-001, YNWRM-2012-01), National Natural Science Foundation of China (51409274, 51309248) and IWHR Project (ZJ1224), SKL-WAC Project (2014QN01).

\section{REFERENCES}

[1] Cheng J., Xie M., The Analysis of Regional Climate Features over Yunnan in Recent 50 Years. Progress In Geography. Vol.27, No 5, pp19-26, 2008, China.

[2] Chen C., "Calculation of Various Cini Coefficients from Different Regions in China and Analysis Using the Nonparametric Model," The Journal of Quantitative \& Technical Economics. No 1, pp133-142, 2007 China.

[3] Qian G., Present Situation and Sustainable Utilization of Water Resources in Yunnan. Yunnan Nongye Keji(supplement). pp8-11, 2009, China.

[4] Li C., Zhang S., Ye X., Problems of Development \& Protection of Lakes on Yunnan Plateau. Yunnan Geology. Vol.24, No 4, pp462-470. 2005, China.

[5] Cheng J., Wang X., Fan L., etc. Variation of Yunnan Climate Zones in Recent 50 Years. Progress In Geography. Vol. 28, No 1, pp18-24, 2009, China
[6] Wu L., Li X., Analysis on Change of Annual Precipitation with Altitude in High Mountain Areas. Yunnan Geographic Environment Research. Vol.16, No 2, pp4-7,2004, China.

[7] Zhang J., An Convenient Method to Calculate Gini Coefficient. J. Shanxi Agric. Univ. (Social Science Edition). Vol.6, No 3, pp275-283. 2007, China

[8] Fei C., Analysis on Lorenz Curves and Gini Coefficients. Journal of Industrial Technological Economics. Vol.28, No 11, pp108-112. 2009, China.

[9] Cheng Y., The Variation and Decomposition of Overall Gini Coefficients in Urban and Rural Areas in China Since its Reform and Opening up. Social Sciences in China. No 27, pp45-60. 2007, China.

[10] Xi M., Hong X., A Simple Method for Calculating the Gini Coefficients. Statistics \& Decision. Vol.2007, No 21, pp161-162, 2007, China.

[11] Shi Z., Huang Y., Liu Y., Research Progress and Tendency in Water Security and City Water Security. China Safety Science Journal. Vol.18, No 4, pp20-27, 2008, China.

[12] Liu H., Zuo Q., Analysis of Water Consumption Structure in Zhengzhou Based on Lorenz Curves and Gini Coefficients. Resource Science. Vol.36, No 10, pp2012-2019. 2014, China.

[13] Xiao W., Qin D., Li W., etc. Model for Distribution of Water Pollutants in A Lake Basin Based on Environmental Gini Coefficient. Acta Science Circumstantiae. Vol.29, No 8, pp1765-1771,2009, China.

[14] Wang J., Lu Y., Zhou J., etc. Analysis of China Resource-environment Gini Coefficient Based on GDP. China Environment Science. Vol.26, No 1, pp111-115, 2006, China. 